\title{
Hippocampus Norepinephrine, Caudate Dopamine and Serotonin, and Behavioral Responses to the Stereoisomers of Amphetamine and Methamphetamine
}

\author{
Ronald Kuczenski, ${ }^{1}$ David S. Segal, ${ }^{1}$ Arthur K. Cho, ${ }^{2}$ and William Melega ${ }^{2}$ \\ 'Psychiatry Department, UC San Diego School of Medicine, La Jolla, California 92093-0603 and 2Medicinal and Molecular \\ Pharmacology Department, UC Los Angeles Health Sciences Center, Los Angeles, California 90025
}

\begin{abstract}
Microdialysis in behaving animals was used to concomitantly characterize the dopamine and 5-HT responses in the caudate and the norepinephrine response in the hippocampus to the D- and L-isomers of amphetamine and methamphetamine. Doses of all four drugs which promoted similar stereotypy responses produced a D-amphetamine-like response profile of dopamine and dopamine metabolites, suggesting that all these drugs interact with dopamine systems to facilitate the release of transmitter. However, in contrast to the similar behavioral profiles, the magnitude of the dopamine responses diverged significantly. In addition, all four drugs increased extracellular norepinephrine and 5-HT, but the relative responses differed markedly from dopamine and from each other. The contrasting structure-activity relationships for these drugs likely reflect their differential potency at the various neuronal uptake transporters in promoting either transmitter release, and/or uptake blockade. In addition, the interaction of each drug at the vesicular transporters, as well as the availability of a cytoplasmic pool of transmitter likely also contribute to the neurotransmitter response.
\end{abstract}

Because of the particularly divergent transmitter response profiles exhibited by L-methamphetamine, its behavioral and neurotransmitter effects were characterized over a more extended range of doses. Although the duration of the increase in extracellular dopamine was clearly proportional to dose, the dose-dependent increases in the magnitude of the dopamine response did not parallel the behavioral profiles. The results of these studies indicate that, while the dopamine, norepinephrine and 5-HT responses to these drugs probably contribute to the expression of stimulant-induced behaviors, simple relationships between the neurotransmitter responses and the behavioral profiles were not evident.

[Key words: microdialysis, caudate, hippocampus, dopamine, norepinephrine, 5-HT, amphetamine, methamphetamine, stereoisomers, stereotypy]

Mesolimbic and mesostriatal dopamine (DA) pathways are crucial components in the motor activating effects of amphetaminelike stimulants (Creese and Iversen, 1974; Kelly, 1977; Cole,

\footnotetext{
Received Jan. 31, 1994; revised July 1, 1994; accepted Aug. 5, 1994.

This work was supported by USPHS Grants DA-04157, DA-01568, DA-02411, and PHS Research Scientist Award MH-70183 to D.S.S.

Correspondence should be addressed to Ronald Kuczenski, Ph.D., Psychiatry Department (0603), UCSD School of Medicine, La Jolla, CA 92093-0603.

Copyright (C) 1995 Society for Neuroscience $0270-6474 / 95 / 151308-10 \$ 05.00 / 0$
}

1978; Sessions et al., 1980). However, the stimulant-induced behavioral response profile does not correspond closely to the quantitative characteristics of the caudate and accumbens DA responses (Kuczenski and Segal, 1989; Kuczenski et al., 1991). This and a variety of other observations (see Segal and $\mathrm{Ku}-$ czenski, 1994, for a review) suggest that other neurotransmitter systems must contribute significantly to the behavioral effects of these drugs.

The microdialysis technique provides a methodology with which to evaluate the relative contribution of multiple neurotransmitter systems in various brain regions to the features of the drug-induced behavioral response in the same animal. Therefore, in the present studies, we have extended our earlier characterizations of the neurotransmitter responses to amphetamine (AMPH) (Kuczenski and Segal, 1989; Kuczenski et al., 1991; Florin et al., 1992; Kuczenski and Segal, 1992a) by concomitantly evaluating caudate DA and serotonin (5-HT), and hippocampus norepinephrine (NE). In addition, we have broadened the scope of these studies to include L-AMPH, and D-, and L-methamphetamine (METH) for comparison with D-AMPH. All of these drugs promote qualitatively similar behavioral responses, but they exhibit different potencies in their interactions with the various biogenic amine transporters (Heikkila et al., 1975; Fischer and Cho, 1979; Andersen, 1987, 1989; Krueger, 1990; Zaczek et al., 1991), and this variation in potency has been implicated in their ability to alter synaptic transmitter dynamics. We reasoned, therefore, that a comparison of the relative efficacies of these $A M P H$ derivatives to enhance the extracellular concentrations of DA, 5-HT, and NE would provide insight into the roles of these transmitter pathways in the various behavioral components of the psychostimulant response.

\section{Materials and Methods}

Rats obtained from Harlan Laboratories (275-300 gm) were maintained four/cage on a $14 \mathrm{hr} / 10 \mathrm{hr}$ light-dark cycle (lights on at 05:00) under standard laboratory conditions, with ad libitum access to food and water for 2 weeks prior to drug treatment. Animals were then stereotaxically implanted with guide cannulae using procedures previously described in detail (Kuczenski and Segal, 1989). Guide cannulae extended $2.6 \mathrm{~mm}$ below the surface of the skull and were aimed at the caudate $(1.0 \mathrm{~mm}$ anterior to bregma, $2.8 \mathrm{~mm}$ lateral, and $6.2 \mathrm{~mm}$ below dura) and the hippocampus ( $5.8 \mathrm{~mm}$ posterior, $4.8 \mathrm{~mm}$ lateral, $7.5 \mathrm{~mm}$ below dura). Following surgery, animals were housed individually and allowed at least 1 weck to recover before receiving any treatment.

Each rat was placed in an experimental chamber and the dialysis probes were inserted on the day prior to treatment (3:00 to 4:00 P.M.) to allow for acclimation to the test environment and for adequate equilibration of the dialysis probes. Concentric microdialysis probes were 


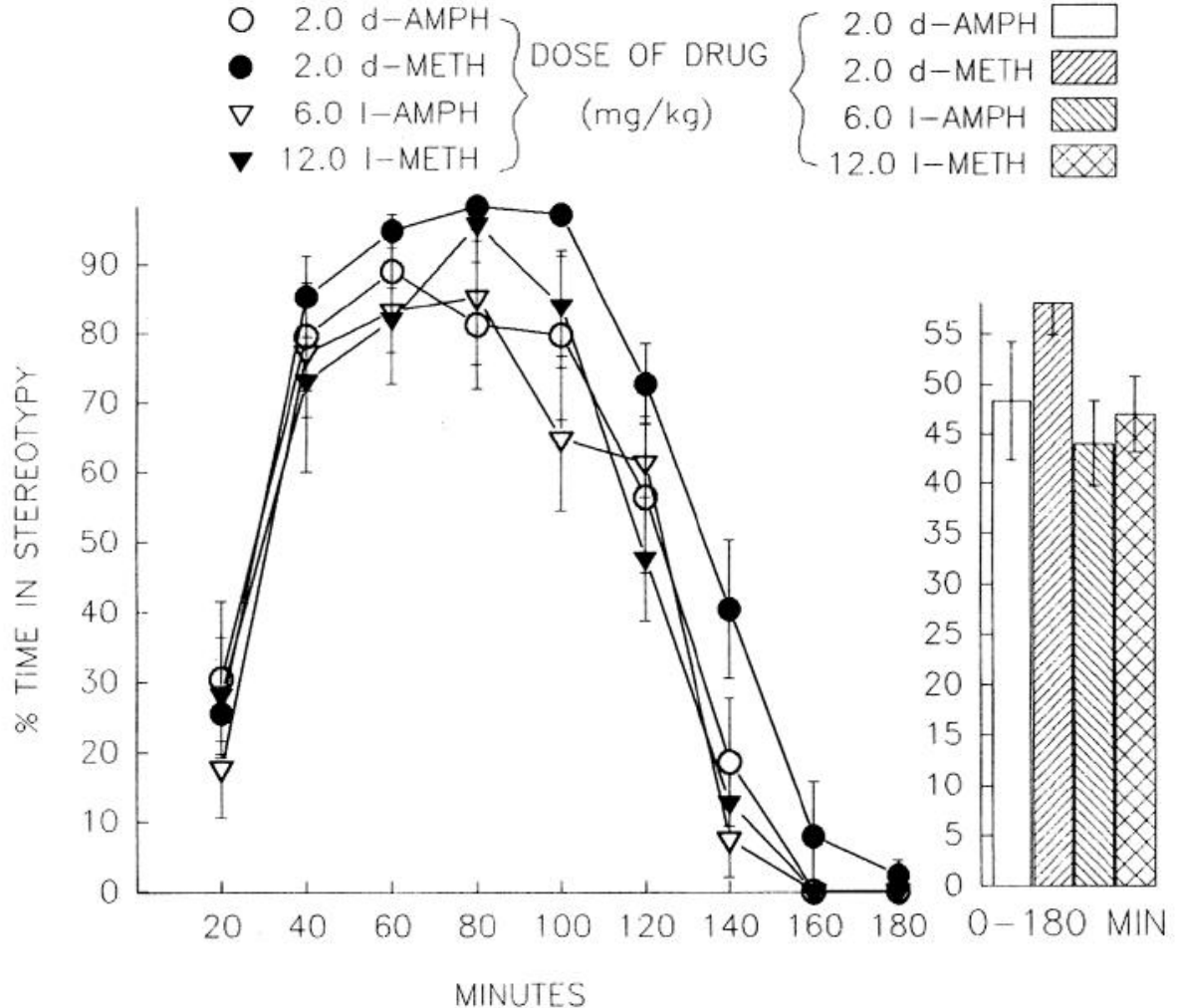

Figure 1. Temporal pattern of stereotypy response to D-AMPH $(n=8)$, L-AMPH $(n=7)$, D-METH $(n=11)$, and L-METH $(n=6)$ of animals undergoing concomitant caudate and hippocampus dialysis. Stereotypy is presented as percentage of total time spent in repetitive movements (mean \pm SEM). Histograms represent the cumulated response over the indicated interval. ANOVA indicated no significant treatment effect. constructed of Spectra/Por hollow fiber (MW cut-off 6000 , o.d. $250 \mu$ ) as previously described (Kuczenski and Segal, 1989). The length of the active probe membrane was $3 \mathrm{~mm}$. Probes were perfused with artificial cerebrospinal fluid $\left(147 \mathrm{~mm} \mathrm{NaCl}, 1.2 \mathrm{~mm} \mathrm{CaCl}_{2}, 0.9 \mathrm{~mm} \mathrm{MgCl}_{2}, 4.0\right.$ $\mathrm{mm} \mathrm{KCl})$ delivered by a microinfusion pump $(2 \mu \mathrm{l} / \mathrm{min})$ via $50 \mathrm{~cm}$ of Micro-line ethyl vinyl acetate tubing connected to a fluid swivel. Dialysate was collected through glass capillary tubing into vials containing $20 \mu \mathrm{l}$ of $25 \%$ methanol, $0.2 \mathrm{~m}$ sodium citrate, $\mathrm{pH} 3.8$. Under these conditions, dialysate DA, 5-HT, NE, and metabolites were stable throughout the collection and analysis interval. Samples were collected outside the experimental chamber to avoid disturbing the animal. Individual probe recoveries, which ranged from $5 \%$ to $9 \%$, were estimated by sampling a standard DA solution in vitro. Preliminary studies indicated that individual probe recoveries for DA, 5-HT, and NE were similar.

The behavioral chambers, described in detail elsewhere (Segal and Kuczenski, 1987; Kuczenski and Segal, 1989), were sound-proofed, and were maintained on a $14 \mathrm{hr} / 10 \mathrm{hr}$ light-dark cycle (lights on at 5 A.M.), with constant temperature and humidity. Animals had continuous access to food and water. Behavioral measures were recorded automatically using computer-assisted techniques and each animal was videotaped for observational rating as previously described (Segal and Kuczenski, 1987). At the end of the experiment, each animal was perfused with formalin for histological verification of probe placements.

Dialysate samples $(40 \mu \mathrm{l})$ were collected every $20 \mathrm{~min}$, and DA, 3,4dihydroxyphenylacetic acid (DOPAC), homovanillic acid (HVA), 3-methoxytyramine (3MT), 5-hydroxyindoleacetic acid (HIAA), and serotonin (5-HT) in caudate samples, or for norepinephrine (NE) in hippocampus were assayed by HPLC with electrochemical detection (HPLC-EC). In all experiments, solutions of standards revealed a clean separation between 3MT and 5-HT. Each HPLC-EC consisted of a 100 $\mathrm{mm} \times 4.6 \mathrm{~mm}$ ODS-C18 $3 \mu$ column (Regis) maintained at $40^{\circ} \mathrm{C}$ for $\mathrm{DA} / 5-\mathrm{HT}$ assays, or at $30^{\circ} \mathrm{C}$ for NE assays. Mobile phase $(0.06 \mathrm{M}$ citric acid, $7 \%$ methanol, $0.1 \mathrm{~mm} \mathrm{Na} \mathrm{A}_{2}$ EDTA, and $0.2 \mathrm{~mm}$ octane sulfonate adjusted to $\mathrm{pH} 4.0-4.5$, for DA $/ 5-\mathrm{HT} ; 4 \%$ methanol and $1.5 \mathrm{~mm}$ octane sulfonate for NE) was delivered at $0.6 \mathrm{ml} / \mathrm{min}$ by a Waters model 510 pump. Amines were detected with Waters 460 detectors with glassy carbon electrodes maintained at $+0.65 \mathrm{~V}$ relative to a $\mathrm{Ag} / \mathrm{AgCl}$ reference electrode. The quantitation limits for DA, 5-HT, and NE were near 2$3 \mathrm{fmol}$. Concentrations were estimated from peak areas using a Waters
Maxima 820 data station. Substances in the dialysates were corrected for individual probe recoveries to account for this source of variability, and, although the exact relationship between dialysate concentration and actual extracellular transmitter content is not clear (Wages et al., 1986; Church and Justice, 1987; Benveniste et al., 1989; Stahle et al., $1991)$, values are presented as corrected dialysate concentration and referred to as extracellular concentration to allow for meaningful comparisons to other data in the literature. Drug-induced neurochemical and behavioral effects were statistically evaluated using one- or twoway repeated measures ANOVA. Group/time comparisons were made using $t$ tests with Bonferroni corrections.

Both stereoisomers of AMPH and D-METH were obtained from NIDA. L-METH was synthesized according to Kishi et al. (1983). Briefly, D-ephedrine (Aldrich Chemical Co., Milwaukee WI) was converted to its chloro derivative with thionyl chloride in benzene. The crude chloride was hydrogenated over $10 \%$ palladium on carbon for $48 \mathrm{hr}$, the mixture was filtered, and the product was isolated by evaporation. Recrystallization from methanol/ether yielded crystals of the hydrochloride whose purity was checked by GC/MS and NMR spectrometry. The enantiomeric purity was evaluated by derivitizing with $N$-TFA-L-prolylchloride (Regis Chem Co., Morton Grove, IL) and found to be $97.5 \%$ and $98.7 \%$ in two separate analyses. All drugs were dissolved in saline and were administered subcutaneously in a volume of $1 \mathrm{ml} / \mathrm{kg}$ body weight at about 10:00 A.M. Doses refer to the free base.

\section{Results}

Basal caudate extracellular concentrations of DA, its metabolites, DOPAC, HVA, and 3MT, and of 5-HT and its metabolite, HIAA, as well as of hippocampus extracellular NE, are summarized in Table 1. These values are similar to earlier results. It should be noted, however, that basal extracellular 5-HT and NE concentrations are low (Kalén et al., 1988, 1989; Abercrombie and Zigmond, 1989; Adell et al., 1989; Globus et al., 1989; Pei et al., 1989; Van Veldhuizen et al., 1990), and in the present experiments were near the limits of assay sensitivity.

Based on our previous results, doses of the D- and L-isomers of AMPH and METH which promoted similar stereotypy re- 


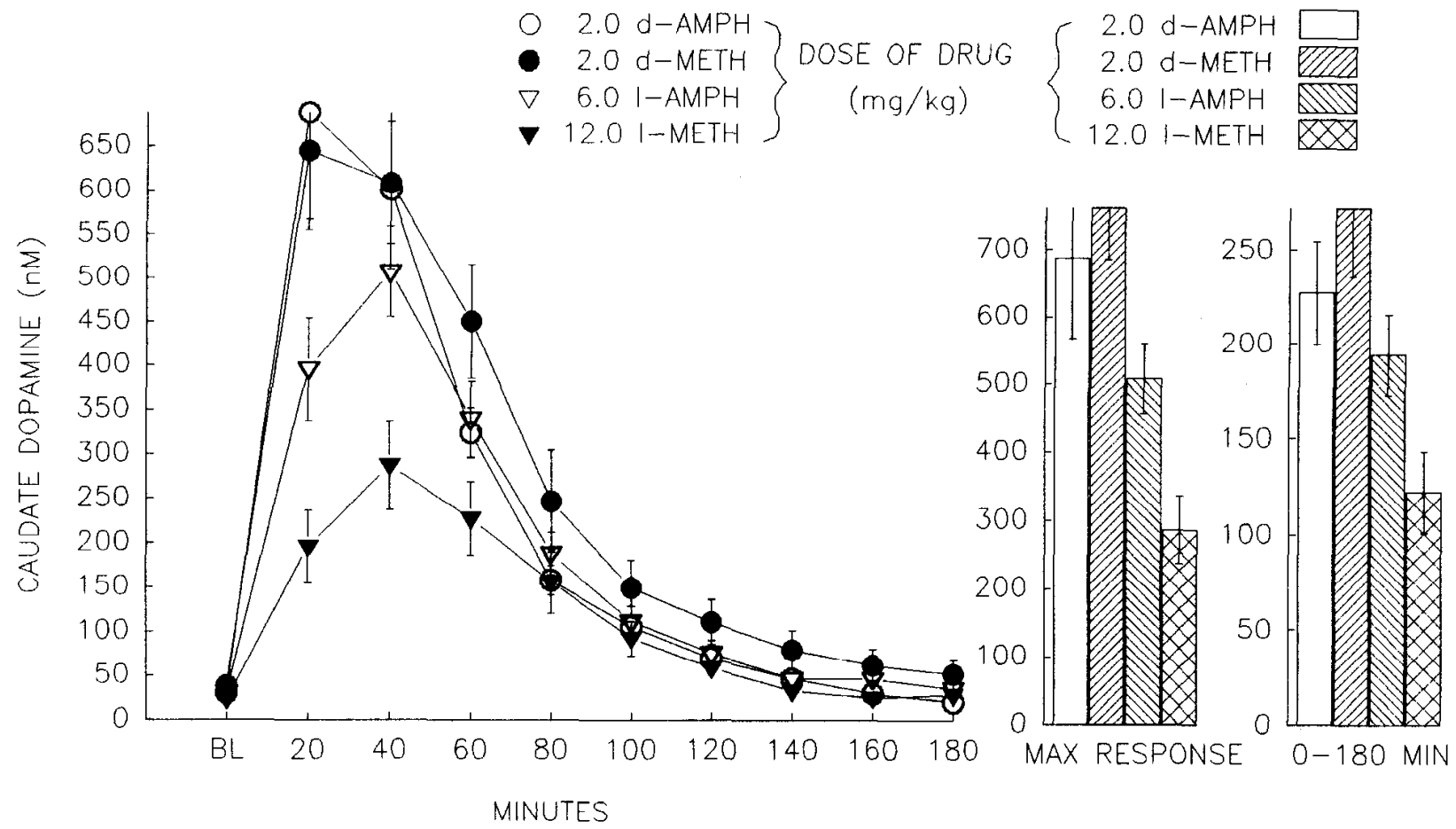

Figure 2. The effects of D-AMPH $(n=5)$, L-AMPH $(n=5)$, D-METH $(n=9)$, and D-METH $(n=6)$ on caudate extracellular dopamine. Each value represents the mean dialysate concentration \pm SEM. Histograms represent the maximal dopamine response and the dopamine response cumulated over the indicated interval. Post-ANOVA comparisons revealed significant differences between drug groups. Maximal and cumulated responses: D-AMPH and D-METH significantly different from L-METH $(p<0.01)$.

sponse patterns were selected for subsequent dialysis studies. The stereotypy responses of dialyzed rats following administration of these doses are presented in Figure 1. All groups exhibited predominantly repetitive head and limb movements, and ANOVA revealed no significant group differences. The D-METH group also engaged in some oral behaviors. In response to $\mathrm{D}^{-}$and L-AMPH, and D-METH, this dose range elicited multiphasic locomotor response profiles (data not shown), in which the prolonged period of focussed stereotypies was associated with the absence of ambulation. In contrast, following L-METH, most animals continued to ambulate, interrupted by episodes of intense stereotypies.

The caudate DA response patterns for these animals are presented in Figure 2. Consistent with our past results, in response to $2 \mathrm{mg} / \mathrm{kg}$ D-AMPH, mean caudate extracellular DA increased approximately 15 -fold to a peak concentration of $688 \pm 121$ $\mathrm{nm}$ during the initial $20 \mathrm{~min}$ interval, then returned to baseline over the next $3 \mathrm{hr}$. Similarly, in response to $2 \mathrm{mg} / \mathrm{kg}$ D-METH, DA increased to a peak concentration of $648 \pm 71 \mathrm{~nm}$ during the initial $20 \mathrm{~min}$ interval and then declined toward baseline. In contrast, in response to both $6 \mathrm{mg} / \mathrm{kg} \mathrm{L}-\mathrm{AMPH}$ and $12 \mathrm{mg} /$ $\mathrm{kg}$ L-METH, peak DA concentrations $(508 \pm 51$ and $287 \pm 49$ $\mathrm{nM}$, respectively) were delayed to the second $20 \mathrm{~min}$ interval, before returning toward baseline. During the initial $20 \mathrm{~min}$ interval, the responses to both D-isomers were significantly higher than the responses to both $\mathrm{L}$-isomers. In addition, the peak responses to both D-AMPH and D-METH were significantly higher than the peak response to L-METH.

Following injection of each AMPH derivative, the DA metabolites, DOPAC and HVA, exhibited responses typical of D-AMPH. Repeated measures ANOVA revealed significant changes over time for both measures (Fig. 3), and a significant time $\times$ group interaction for HVA. All four drugs also significantly increased extracellular 3MT concentrations (Fig. 4), but there were no significant group effects, nor time $\times$ group interactions.

The responses of caudate 5-HT to the four AMPH derivatives are presented in Figure 5. All four drugs increased extracellular 5-HT. However, in contrast to what was observed for caudate DA, both stereoisomers of METH promoted similar and significantly higher peak 5-HT concentrations than either stereoisomer of AMPH (Fig. 5, histograms). Caudate HIAA concentrations were stable throughout the experiment, and no significant drug effects were observed (data not shown).

All four drugs also increased hippocampal NE concentrations (Fig. 6). Similar to our previous results, $2 \mathrm{mg} / \mathrm{kg}$ D-AMPH increased NE to a maximum of $29.3 \pm 3.1 \mathrm{nM}$, about 20 -fold over baseline, during the second $20 \mathrm{~min}$ interval. L-AMPH $(6 \mathrm{mg} /$ $\mathrm{kg}$ ) produced a comparable effect, increasing NE concentrations to $32.0 \pm 8.9 \mathrm{nM}$. In contrast, D-METH promoted an increase in NE to $12.0 \pm 1.2 \mathrm{nM}$ which was significantly lower than all other groups, whereas L-METH promoted an increase to 64.8 $\pm 4.9 \mathrm{nM}$, which was significantly higher than all other groups. Maximal NE concentrations and cumulative responses are summarized in Figure 6 (histograms).

Because of the particularly divergent transmitter response profiles exhibited by L-METH, (i.e., this drug promoted the lowest DA response, but the highest NE response; see Figs. 2, 6), we further examined its behavioral and neurotransmitter effects over a more extended range of doses $(3-18 \mathrm{mg} / \mathrm{kg})$, and the results are summarized in Figures 7-10. All doses promoted locomotor activation which was interrupted by progressively longer episodes of repetitive head movements as the dose was increased (Fig. 7). No dose resulted in a continuous phase of 
Table 1. Baseline dialysate concentrations (nM)

\begin{tabular}{|c|c|c|c|c|c|c|}
\hline \multicolumn{6}{|c|}{ Caudate } & \multirow{2}{*}{$\begin{array}{l}\text { Hippo- } \\
\text { cam- } \\
\text { pus } \\
\mathrm{NE}\end{array}$} \\
\hline $\mathrm{DA}$ & DOPAC & HVA & $3 \mathrm{MT}$ & HIAA & $5-\mathrm{HT}$ & \\
\hline $\begin{array}{l}28.2 \\
\pm 1.9\end{array}$ & $\begin{array}{l}4258 \\
\pm 307\end{array}$ & $\begin{array}{l}3190 \\
\pm 222\end{array}$ & $\begin{array}{l}9.8 \\
\pm 0.8\end{array}$ & $\begin{array}{l}2110 \\
\pm 118\end{array}$ & $\begin{array}{l}1.2 \\
\pm 0.1\end{array}$ & $\begin{array}{l}1.6 \\
\pm 0.1\end{array}$ \\
\hline
\end{tabular}

Values are dialysate concentrations (nM) corrected for individual probe recoveries, and are presented as means \pm SEM; $n=47$ for caudate DA and metabolites; $n$ $=42$ for caudate 5 -HT; $n=49$ for hippocampus NE.

focussed stereotypies in the absences of locomotion, or in the appearance of oral stereotypies.

The temporal pattern of caudate extracellular DA as a function of dose of $\mathrm{L}$-METH is presented in Figure 8. The duration of the increase in extracellular DA was clearly proportional to dose. However, the maximal increases in caudate DA at the three higher doses were all significantly greater than at $3 \mathrm{mg} /$ $\mathrm{kg}$, but not significantly different from each other (Fig. 8). Increasing the dose of L-METH produced AMPH-like effects on caudate DA metabolites (data not shown), including dose-related decreases in DOPAC and HVA concentrations and increases in 3MT which were dose-dependent in both magnitude and duration.

Both caudate 5-HT (Fig. 9) and hippocampal NE (Fig. 10) were increased by L-METH, and the increases were dose-dependent both in magnitude and duration. In each case, however, maximal increases following 12 and $18 \mathrm{mg} / \mathrm{kg} \mathrm{L}$-METH were identical.

\section{Discussion}

The results of this study indicate that the stereoisomers of AMPH and METH can promote similar behavioral effects which are associated with markedly different $\mathrm{DA}, \mathrm{NE}$, and 5-HT responses. Most evidence suggests that the AMPH derivatives alter biogenic amine function by their interactions with the transmitter uptake process. Thus, the contrasting structure-activity relationships for these drugs likely reflect their differential potency at each transmitter uptake transporter.

With regard to the effects of these drugs on DA, our results indicate that D-AMPH and D-METH promoted equivalent increases in extracellular DA, whereas the responses to the two L-isomers were lower. In general, these results are consistent with previous in vitro studies which indicated that D-AMPH and D-METH are about equipotent in their abilities to release DA (Fischer and Cho, 1979) or inhibit its uptake (Krueger, 1990), and that D- and L-AMPH exhibit a three- to sevenfold difference in potency at the DA transporter (Heikkila et al., 1975; Fischer and Cho, 1979; Andersen, 1987, 1989; Zaczek et al., 1991). Relative potencies of L-METH are not available.

The AMPH derivatives produced NE and 5-HT response patterns that were distinct from DA and from each other. Thus, whereas D-METH was relatively potent in increasing caudate $\mathrm{DA}$, it produced the smallest increase in hippocampal NE. In contrast, L-METH promoted the smallest increase in caudate DA, but the greatest increase in hippocampal NE, and $D$ - and L-AMPH were approximately equipotent in increasing NE at doses that produced significantly different $D A$ responses. At the same time, the relative potency pattern for 5-HT was substantially different than for both catecholamines. Thus, whereas both
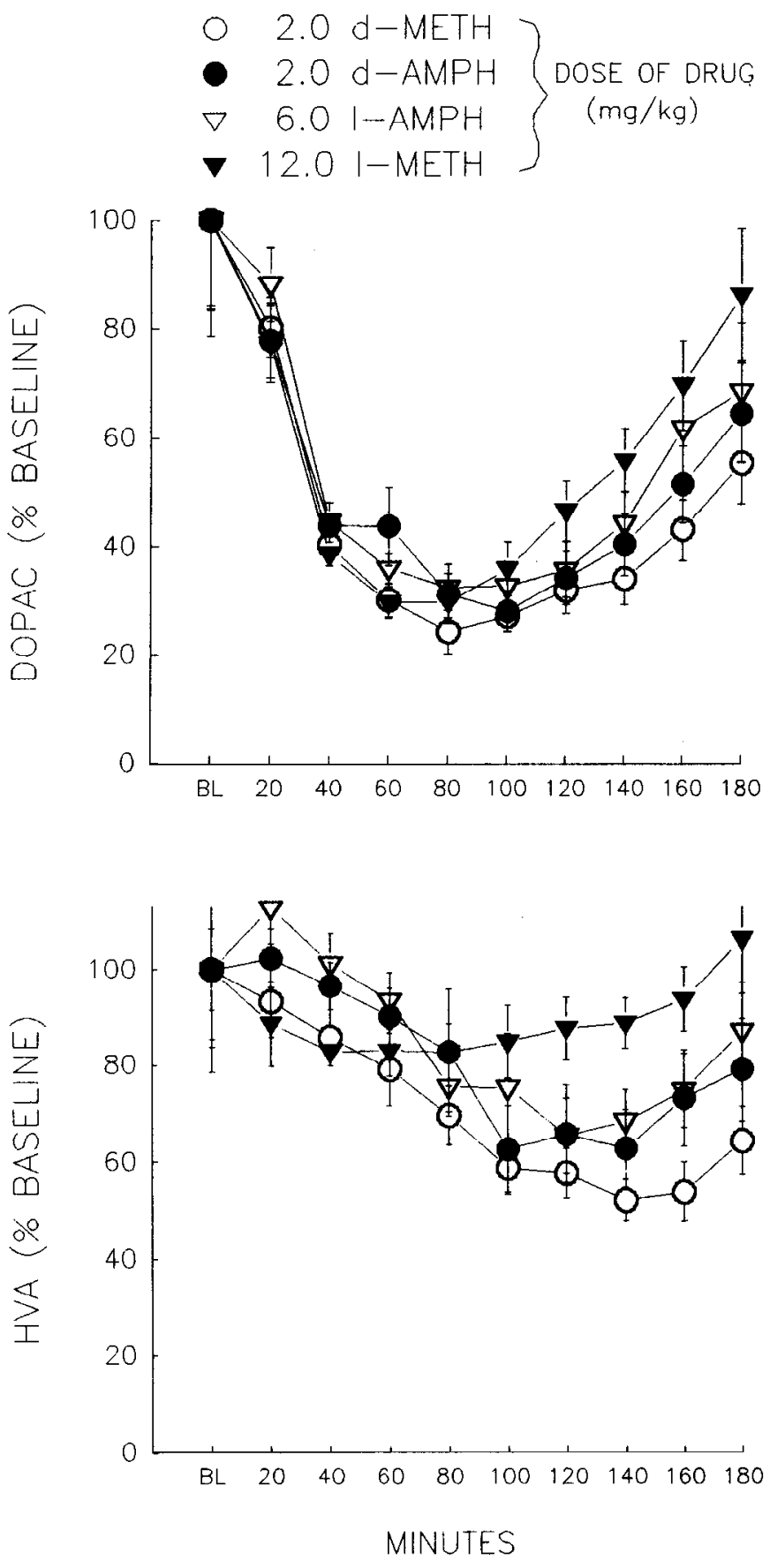

Figure 3. Response of the caudate dopamine metabolites, DOPAC and HVA, to D- and L-AMPH, and D- and L-METH. Each value represents the mean dialysate concentration, presented as percent of baseline, \pm SEM. Significance of effects was determined using repeated measures two-way ANOVA. DOPAC: time, $F_{(12.240)}=107(p<0.0001)$; drug, $F_{(3.20)}=0.93(\mathrm{NS})$; interaction, $F_{(36.240)}=1.19$ (NS). HVA: time, $F_{(12.240)}=19.85(p<0.0001) ; \mathrm{drug}, F_{(3.20)}=1.34(\mathrm{NS})$; interaction, $F_{(36,240)}$ $=1.71(p<0.01)$.

D-isomers produced virtually identical DA responses, D-METH increased 5-HT about threefold greater than D-AMPH. Furthermore, although D-AMPH and D-METH were each more potent than their L-isomers in increasing extracellular DA, the 5-HT responses to the d-stereoisomers were similar to their respective L-isomers. This differential neurotransmitter responsivity is further evident in the dose-response effects of L-METH; 


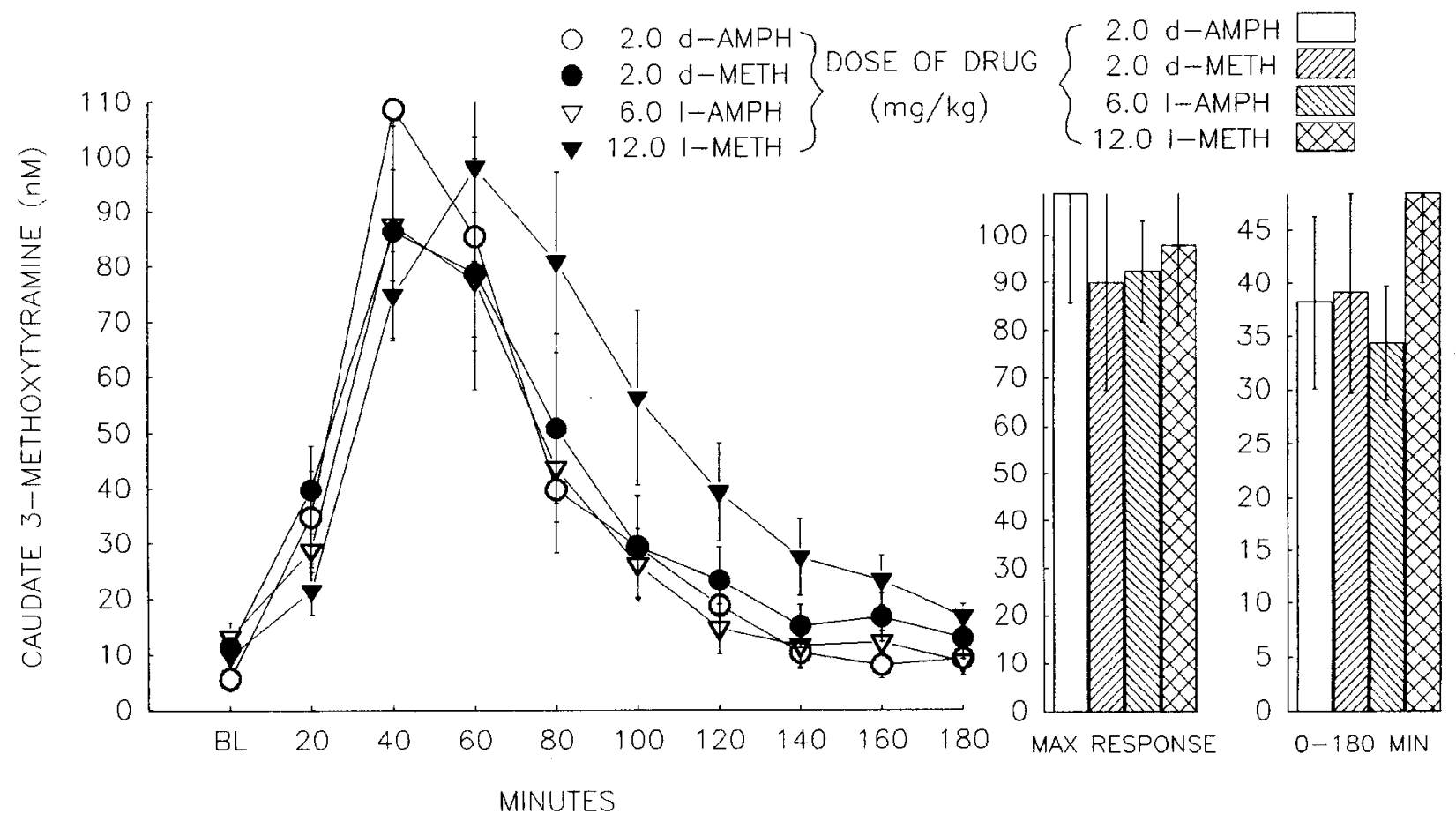

Figure 4. Temporal pattern of caudate 3MT response to D- and L-AMPH, and D- and L-METH. Each value represents the mean dialysate concentration \pm SEM. Histograms represent the maximal 3MT response and the 3MT response cumulated over the indicated interval. ANOVA of the maximum or cumulated responses indicated no significant treatment effects.

that is, maximal extracellular DA concentrations were achieved following the $6 \mathrm{mg} / \mathrm{kg}$ dose (Fig. 8), whereas this dose increased extracellular 5-HT less than half-maximally relative to the higher doses (Fig. 9).
It is likely that these different neurotransmitter response patterns reflect the drugs' interactions at the various transporters, resulting in either carrier-mediated release, and/or uptake blockade. The nature of this interaction has only been well established

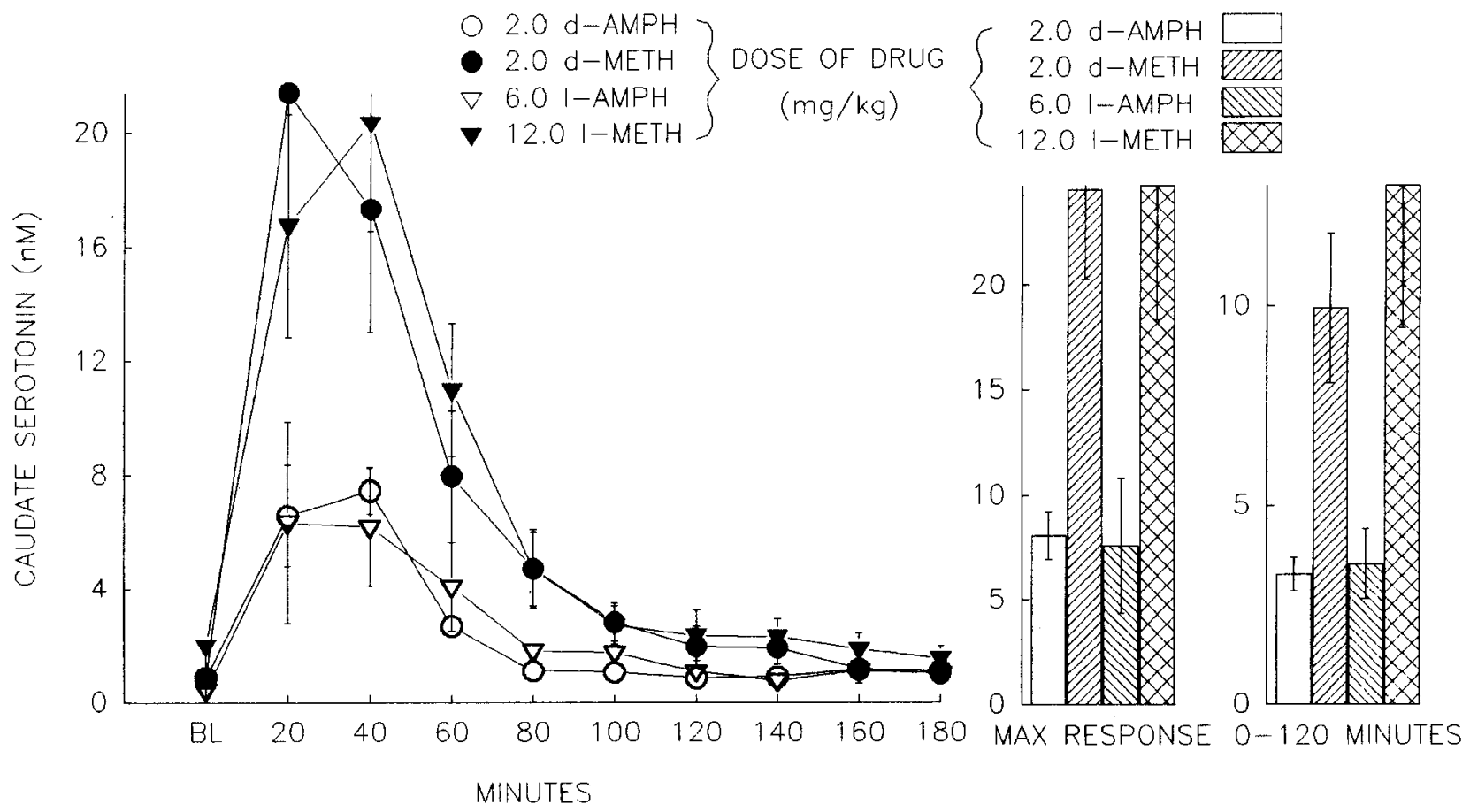

Figure 5. Effects of D-AMPH $(n=5)$, L-AMPH $(n=3)$, D-METH $(n=6)$, and L-METH $(n=6)$ on caudate dialysate 5-HT. Each value represents the mean dialysate concentration \pm SEM. Histograms represent the maximal 5-HT response and the 5-HT response cumulated over the indicated interval. Post-ANOVA comparisons revealed significant group effects. Maximal and cumulated 5-HT response: D- and L-METH significantly different from D- and L-AMPH $(p<0.01)$. 


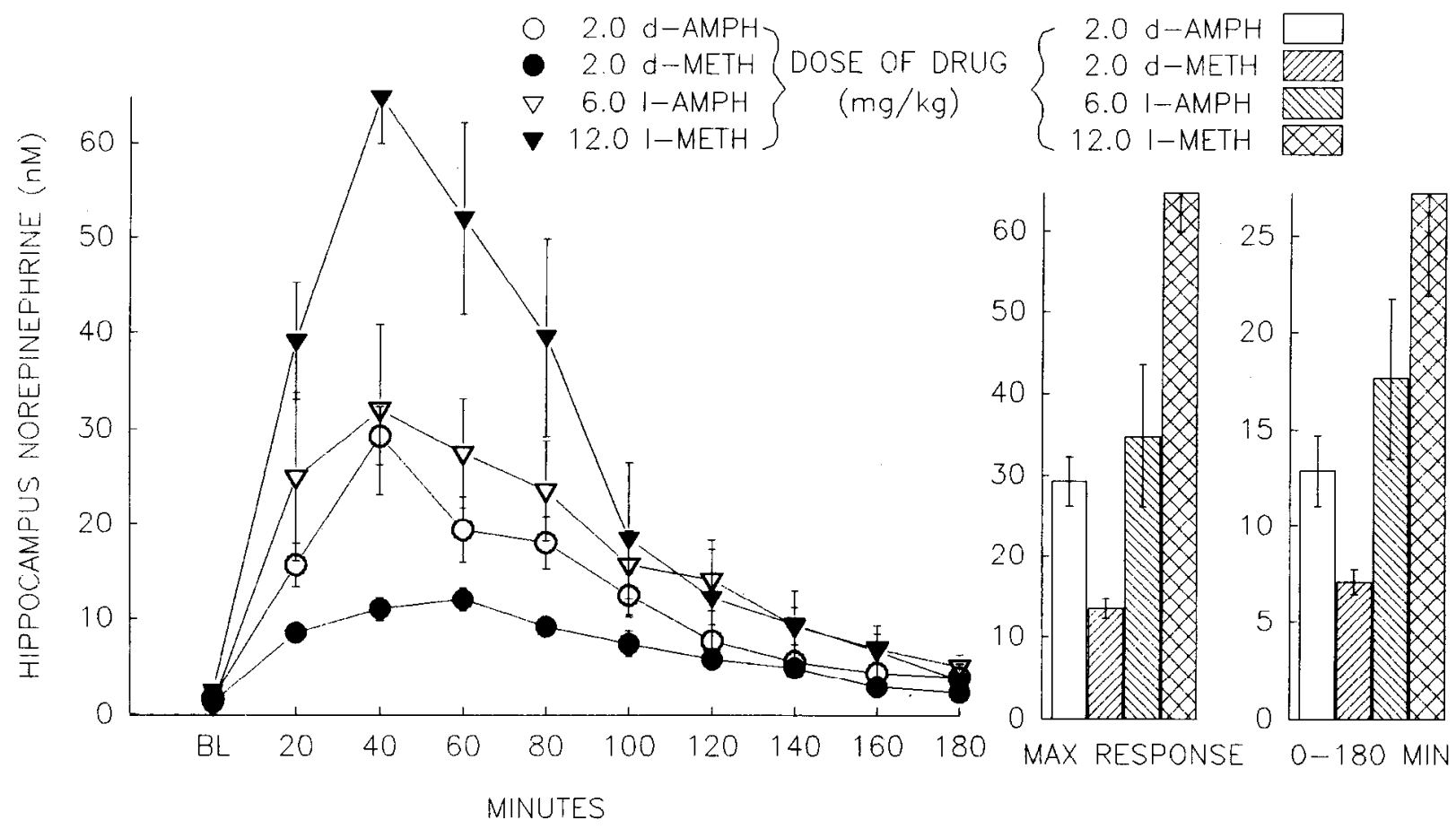

Figure 6. Temporal pattern of hippocampus NE response to D-AMPH $(n=7)$, L-AMPH $(n=7)$, D-METH $(n=8)$, and L-METH $(n=4)$. Each value represents the mean \pm SEM. Histograms represent the maximal NE response and the NE response cumulated over the indicated interval. Post-ANOVA comparisons revealed significant group effects. Maximal NE response: D-METH significantly different from D-AMPH ( $p<0.05$ ), L-AMPH $(p<0.05)$, and L-METH $(p<0.01)$; L-METH significantly different from all other groups $(p<0.01)$. Cumulated NE response: D-AMPH significantly different from L-METH $(p<0.05)$; D-METH significantly different from L-AMPH $(p<0.05)$ and L-METH $(p<0.01)$.

for AMPH at the DA nerve terminal (see Kuczenski and Segal, 1994 , for a recent review). However, previous observations, as well as the present data, provide some insight into the actions of these drugs at the three neurotransmitter systems. With regard to DA, the DA metabolite profiles for all the drugs are more consistent with a D-AMPH-like release process rather than with uptake blockade. We have previously shown that DA uptake blockers produce little change in caudate extracellular DOPAC

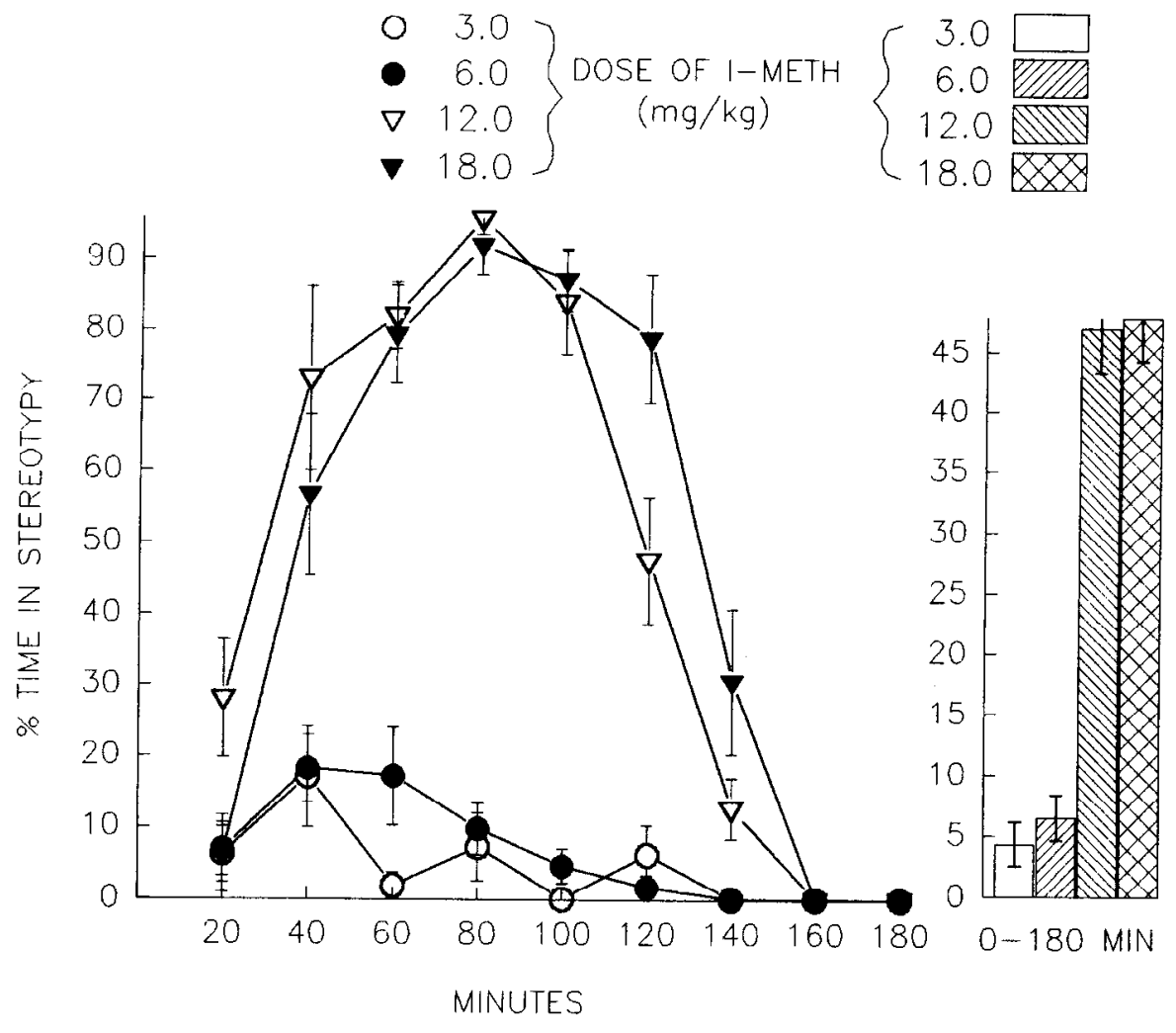

Figure 7. Temporal pattern of stereotypy response to increasing doses of L-METH $[3 \mathrm{mg} / \mathrm{kg}(n=7), 6 \mathrm{mg} / \mathrm{kg}(n$ $=11), 12 \mathrm{mg} / \mathrm{kg}(n=6), 18 \mathrm{mg} / \mathrm{kg}(n$ $=8)$ ] of animals undergoing concomitant caudate and hippocampus dialysis. Stereotypy is presented as percentage of total time spent in repetitive movements (mean \pm SEM). Histograms represent the cumulated response over the indicated interval. ANOVA revealed a significant dose effect during the $0-180$ min interval $(p<0.001)$, but not during the $0-60 \mathrm{~min}$ interval. 


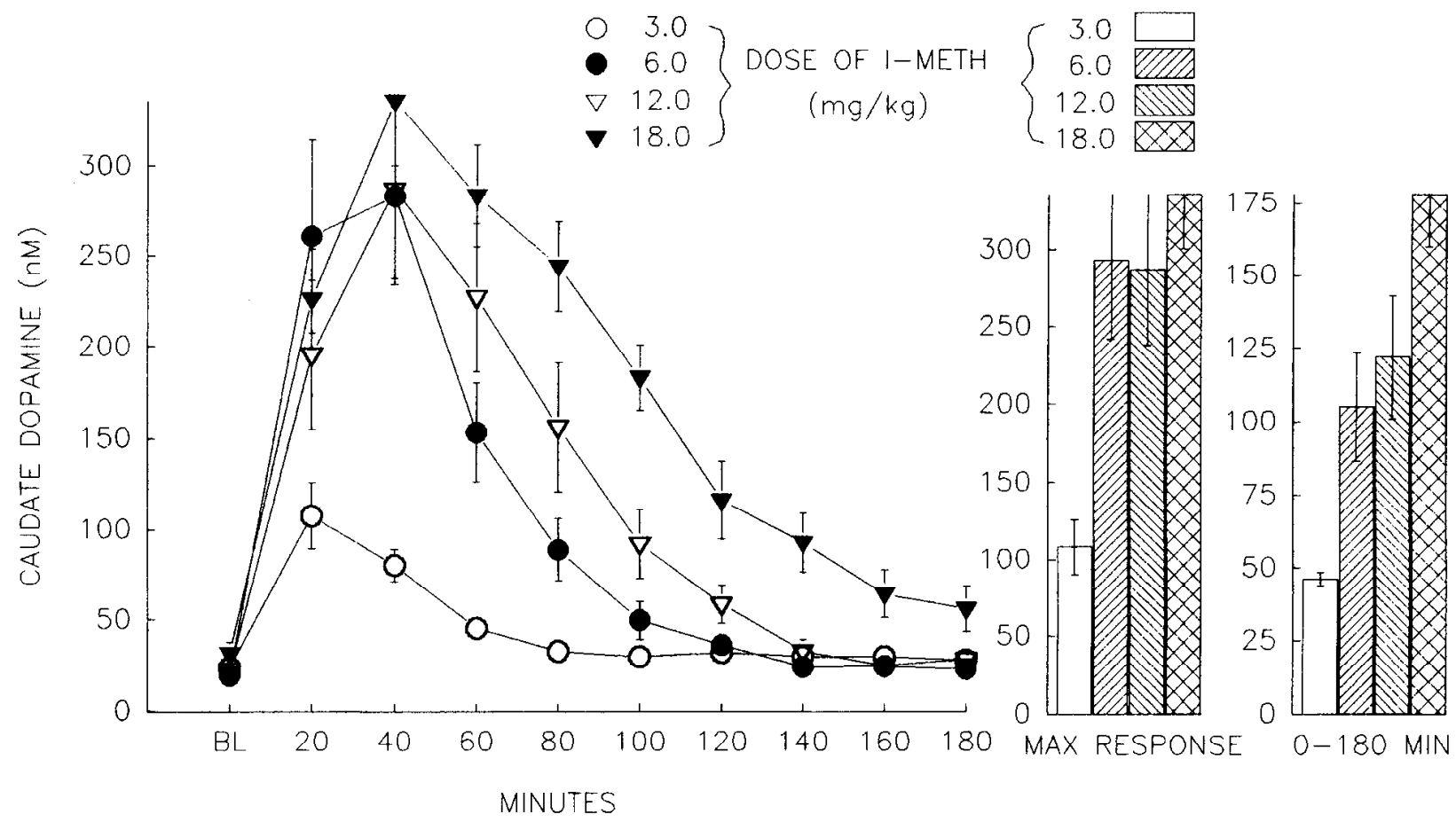

Figure 8. Temporal pattern of caudate dopamine response to increasing doses of L-METH: $3 \mathrm{mg} / \mathrm{kg}(n=7), 6 \mathrm{mg} / \mathrm{kg}(n=8), 12 \mathrm{mg} / \mathrm{kg}(n=6)$, and $18 \mathrm{mg} / \mathrm{kg}(n=7)$. Each value represents the mean dialysate concentration \pm SEM. Histograms represent the maximal dopamine response and the dopamine response cumulated over the indicated interval. Post-ANOVA group comparisons revealed significant differences between doses. Maximal responses: $3 \mathrm{mg} / \mathrm{kg}$ significantly different from all other doses $(p<0.01)$. Cumulated responses: $3 \mathrm{mg} / \mathrm{kg}$ significantly different from all other doses $(p<0.01) ; 6 \mathrm{mg} / \mathrm{kg}$ significantly different from $18 \mathrm{mg} / \mathrm{kg}(p<0.05)$.

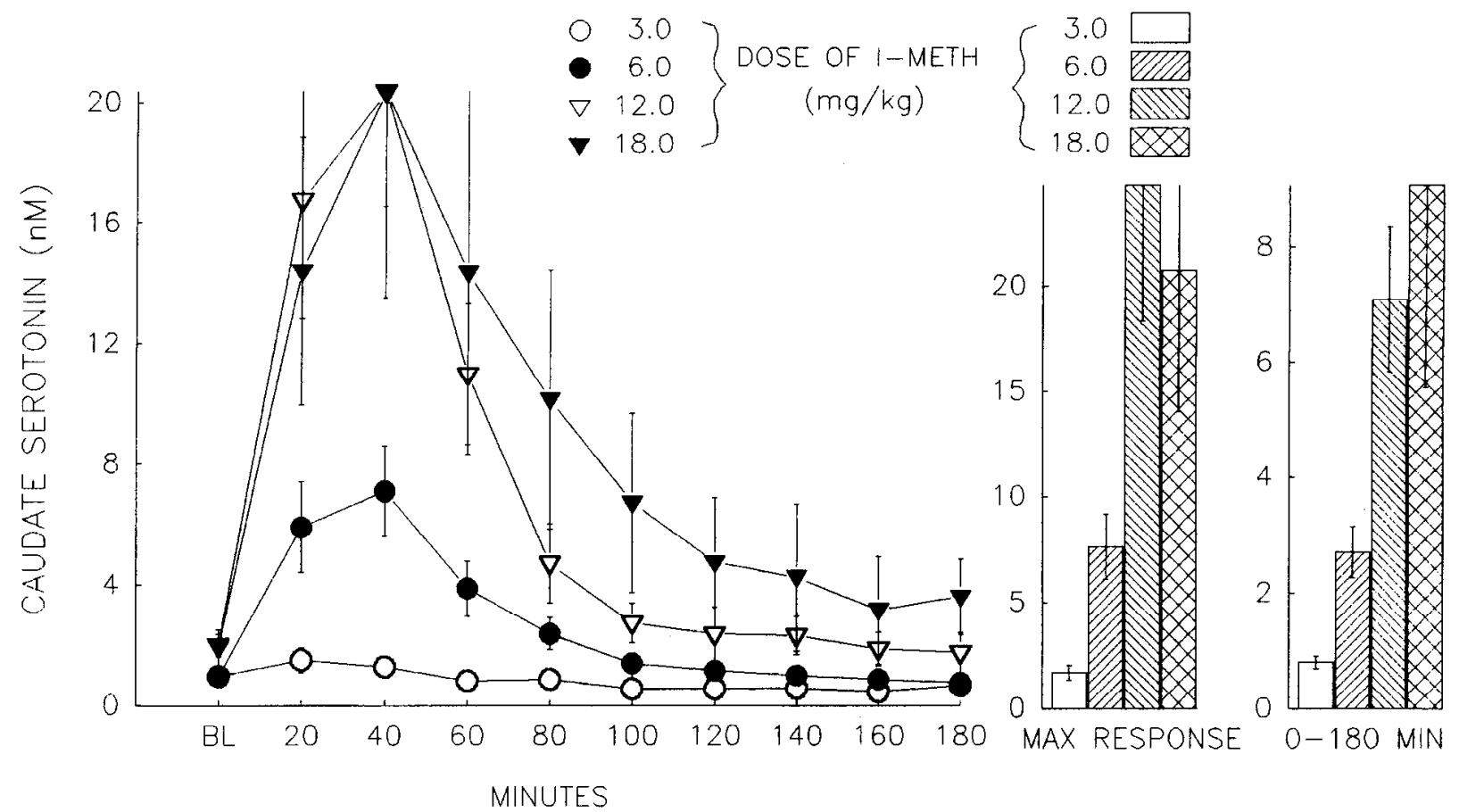

Figure 9. Effects of increasing dose of L-METH on caudate dialysate $5-\mathrm{HT} ; 3 \mathrm{mg} / \mathrm{kg}(n=6), 6 \mathrm{mg} / \mathrm{kg}(n=8), 12 \mathrm{mg} / \mathrm{kg}(n=6)$, and $18 \mathrm{mg} / \mathrm{kg}$ $(n=6)$. Each value represents the mean dialysate concentration \pm SEM. Histograms represent the maximal 5-HT response and the 5-HT response cumulated over the indicated interval. Post-ANOVA group comparisons revealed significant differences between doses. Maximal and cumulated 5 -HT response: $3 \mathrm{mg} / \mathrm{kg}$ significantly different from all other doses $(p<0.01) ; 6 \mathrm{mg} / \mathrm{kg}$ significantly different from $12 \mathrm{mg} / \mathrm{kg}$ and $18 \mathrm{mg} / \mathrm{kg}(p<$ $0.05)$. 


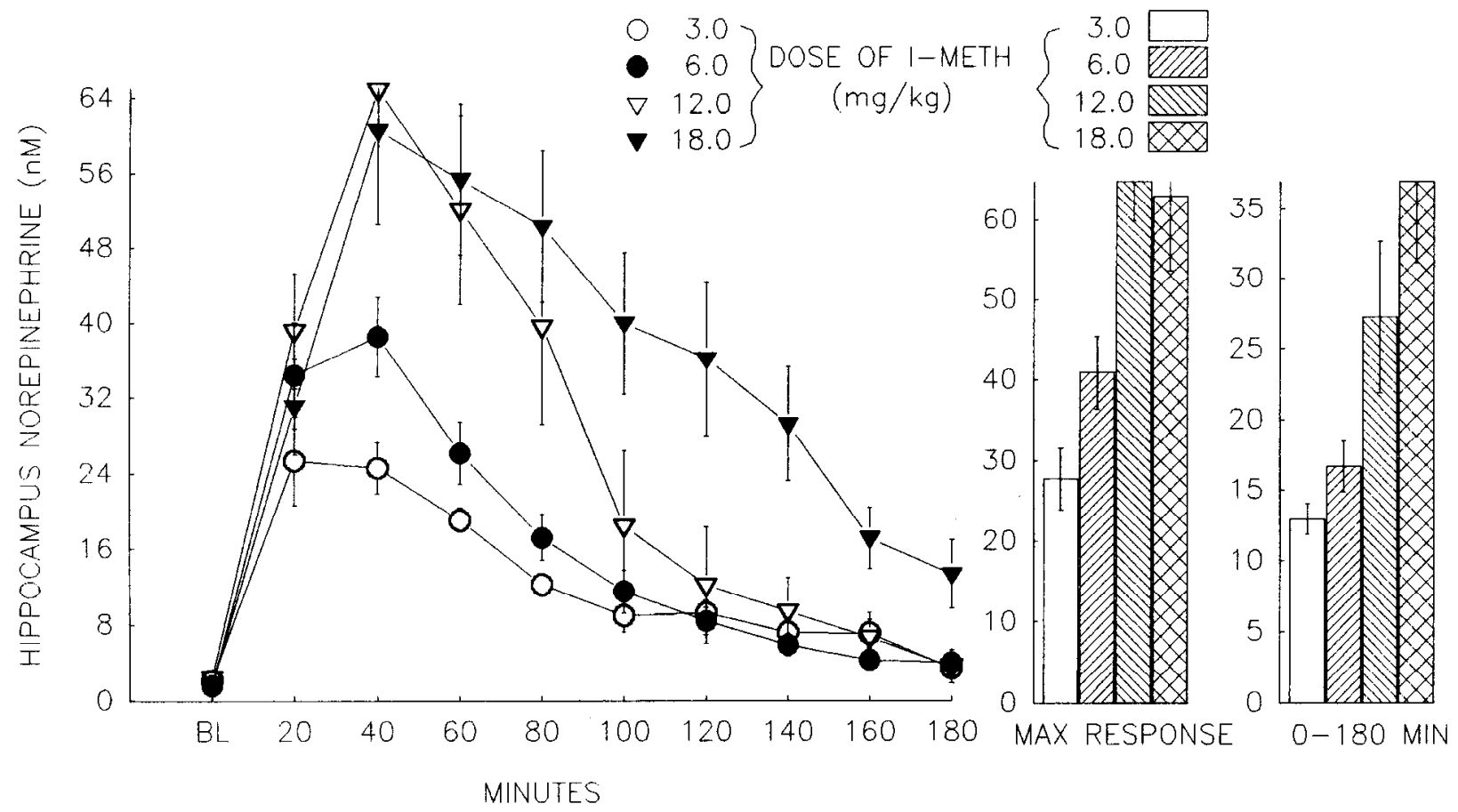

Figure 10. Temporal pattern of hippocampus NE response to increasing doses of L-METH: $3 \mathrm{mg} / \mathrm{kg}(n=6), 6 \mathrm{mg} / \mathrm{kg}(n=9), 12 \mathrm{mg} / \mathrm{kg}(n=4)$, and $18 \mathrm{mg} / \mathrm{kg}(n=8)$. Each value represents the mean \pm SEM. Histograms represent the maximal NE response and the NE response cumulated over the indicated interval. Post-ANOVA comparisons revealed significant group effects. Maximal NE response: $3 \mathrm{mg} / \mathrm{kg}$ significantly different from $12 \mathrm{mg} / \mathrm{kg}(p<0.05)$ and $18 \mathrm{mg} / \mathrm{kg}(p<0.01) ; 6 \mathrm{mg} / \mathrm{kg}$ significantly different from $18 \mathrm{mg} / \mathrm{kg}(p<0.05)$. Cumulated NE response: $3 \mathrm{mg} / \mathrm{kg}$ significantly different from $12 \mathrm{mg} / \mathrm{kg}(p<0.05)$ and $18 \mathrm{mg} / \mathrm{kg}(p<0.01) ; 6 \mathrm{mg} / \mathrm{kg}$ significantly different from $18 \mathrm{mg} / \mathrm{kg}(p<0.05)$.

or HVA concentrations (Kuczenski et al., 1991; Kuczenski and Segal, 1992b), whereas D-AMPH profoundly decreases the concentration of these metabolites (Zetterstrom et al., 1983; Zetterstrom et al., 1986; Kuczenski and Segal, 1989, 1992b; Pehek et al., 1990). In the present studies, all the drugs promoted D-AMPH-like DA metabolite response profiles (Fig. 3). It is unlikely that the decline in metabolites reflects AMPH inhibition of monoamine oxidase, since most evidence suggests that such an effect occurs only at relatively high AMPH concentrations (Green and El Hait, 1980; Miller et al., 1980). Although the exact mechanism underlying the decreases in DOPAC and HVA is not fully understood, it does appear to differentiate stimulants that are DA releasers from DA uptake blockers. Other evidence also suggests that L-AMPH (Heikkila et al., 1975; Fischer and Cho, 1979) and D-METH (Fischer and Cho, 1979) can act as DA releasers. Nevertheless, although the metabolite data are parsimonious with a release mechanism, a prominent role for uptake blockade in the action of these AMPH derivatives cannot be ruled out at the present time.

Some evidence suggests that 5-HT may also be released via a carrier-mediated process. Thus, using the synaptosome superfusion technique, Raiteri et al. (1975) reported that D-AMPH releases 5-HT. Subsequently, a variety of substituted AMPHs, including D-METH, have been shown to release 5-HT, and this release could be blocked by 5-HT uptake blockers (Berger et al., 1992; Rudnick and Wall, 1992; Sabol et al., 1992), consistent with a carrier-mediated mechanism.

With regard to NE, whether AMPH interacts with the brain NE transporter solcly as an uptake blocker, or to also facilitate NE release has not been firmly established, since in vitro efforts to detect AMPH-induced NE release have been mixed (Heikkila et al., 1975; Kalisker et al., 1975; Raiteri et al., 1975; Rutledge,
1978). However, we have recently shown that, although at low doses, AMPH appears to act primarily as an uptake blocker, as the dose is increased into the range used in the present studies, NE release predominates (Florin et al., 1994). Based on these data, we have speculated (Kuczenski, 1983; Florin et al., 1994), as have others with regard to the sympathetic nervous system (Trendelenburg, 1991), that a releasing action by AMPH requires mobilization of vesicular NE into the cytoplasm, and several mechanisms have been postulated by which AMPH, particularly at higher doses, can produce NE mobilization (Johnson et al., 1982; Phillips, 1982; Sulzer and Rayport, 1990). In this regard, AMPH exhibits a lower $\mathrm{IC}_{50}$ in its interaction with the neuronal transporter than with the vesicular transporter (Schumann and Philippu, 1962; Philippu and Beyer, 1973; Ferris and Tang, 1979; Knepper et al., 1988). Thus, AMPH would be expected to effectively inhibit NE uptake at lower doses than required to mobilize vesicular NE for release.

In vitro, D-AMPH and L-AMPH are equipotent as inhibitors of NE uptake into the nerve terminal (Heikkila et al., 1975; Andersen, 1989), and, if uplake blockade predominated at the doses used in the present studies, these isomers should produce comparable increases in extracellular NE. However, our in vivo results (Fig. 6) suggest that the D-isomer is significantly more potent than the L-isomer in increasing extracellular NE. In this regard, D-AMPH is 10-fold more potent than L-AMPH in interacting with the vesicular NE transporter (Ferris and Tang, 1979), and therefore, at equipotent uptake blocking doses, d-AMPH might be expected to disrupt vesicular stores of NE to a greater extent than L-AMPH. Thus, our results may be explained by the fact that D-AMPH increases cytoplasmic transmitter to a greater extent. Furthermore, the extremely high levels of extracellular NE observed following 12-18 mg/kg L-METH 
may reflect high cytoplasmic concentrations of this drug which effectively mobilize vesicular transmitter. This is consistent with our finding that L-METH and L-AMPH at the same dose $(6 \mathrm{mg} /$ $\mathrm{kg}$ ) promote similar increases in extracellular NE (compare Figs. 6,10 ). The relatively small NE response to $\mathbf{D}-\mathrm{METH}$ may reflect low potency at either the neuronal and/or the vesicular transporter.

In summary, in considering the mechanisms which contribute to the relative response patterns of the three biogenic amines to the AMPH derivatives, the potency of each drug at both the neuronal and vesicular transporters, as well as the availability of a cytoplasmic pool of transmitter must be considered. Although these drugs are potent uptake blockers at the DA and 5-HT neuronal transporters, the cytoplasmic localization of the enzymes required for DA and 5-HT synthesis may permit sufficient accumulation of cytoplasmic transmitter to sustain release through a carrier-mediated process. In contrast, in the absence of a cytoplasmic NE pool, low doses of the AMPH derivatives act predominantly as uptake blockers at the neuronal transporter. However, as the dose is increased, the AMPH derivatives can accumulate in the cytoplasm to sufficiently high concentrations to disrupt vesicular storage, thus facilitating transmitter release from all three biogenic amine nerve terminals.

We have previously described the profound dissociation which occurs between the quantitative features of the behavioral and caudate and accumbens DA responses to psychomotor stimulants under a variety of conditions (Callaway et al., 1989; Segal and Kuczenski, 1992; Kuczenski et al,, 1990, 1991), and the present results further support this observation. First, whereas the AMPH derivatives generally produced qualitatively and quantitatively similar stereotypy profiles, the magnitude of the caudate DA responses diverged significantly. Second, although the cumulated caudate DA and stereotypy responses to L-METH exhibited parallel dose response characteristics, this relationship appcars to reflect the dose-dependent duration of the effects, and, in fact, the early period of stereotypy (Fig. 7) did not parallel the initial or maximal DA responses (Fig. 8).

It should be noted, however, that, in contrast to the marked differences in the caudate DA responses to the AMPH derivatives at behaviorally similar doses, these drugs produced comparable 3MT responses (Fig. 4). We have previously noted that extracellular concentrations of 3MT and DA appear to reflect different aspects of synaptic DA dynamics and have suggested that 3MT might represent an alternative index of receptor-relevant DA concentrations (Kuczenski and Segal, 1992b). Our results are consistent with this hypothesis, and suggest that a further examination of DA-3MT-behavior relationships is warranted. However, it is important to note that, as with extracellular DA, the 3MT response (Fig. 4) is temporally dissociated from the behavioral response (Fig. 1). Therefore, caudate DA function alone cannot account for the stimulant behavioral profile. That AMPH and its derivatives increased extracellular concentrations of NE and 5-HT, as well as DA, is consistent with this proposal. However, the behavioral responses to these drugs were similar at doses which produced markedly different effects on all three neurotransmitters. Therefore, an understanding of the contribution of these various effects of AMPH to the behavioral response will require further study.

In summary, the four AMPH derivatives all increase extracellular concentrations of DA and 5-HT in the caudate and NF, in the hippocampus. However, their neurotransmitter response patterns diverged considerably. This range of response patterns may be due to differential interactions of these drugs with the biogenic amine transporters. Although it is likely that all these transmitter responses contribute to the expression of stimulantinduced behaviors, additional studies will be required to more accurately define their specific roles.

\section{References}

Abercrombie ED, Zigmond MJ (1989) Partial injury to central noradrenergic neurons: reduction of tissue norepinephrine content is greater than reduction of extracellular norepinephrine measured by microdialysis. J Neurosci 9:4062-4067.

Adell A, Sarna GS, Hutson PH, Curzon G (1989) An in vivo dialysis and behavioural study of the release of 5-HT by $p$-chloroamphetamine in reserpine-treated rats. Br J Pharmacol 97:206-212.

Andersen PH (1987) Biochemical and pharmacological characterization of [ $\left.{ }^{3} \mathrm{H}\right]$ GBR 12935 binding in vitro to rat striatal membranes: labeling of the dopamine uptake carrier. J Neurochem 48:1887-1896.

Andersen PH (1989) The dopamine uptake inhibitor GBR 12909: selectivity and molecular mechanism of action. Eur J Pharmacol 166: 493-504.

Benveniste H, Hansen AJ, Ottosen NS (1989) Determination of brain interstitial concentrations by microdialysis. J Neurochem 52:17411750.

Berger UV, Gu XF, Azmitia EC (1992) The substituted amphetamines 3,4-methylenedioxymethamphetamine, methamphetamine, $p$-chloroamphetamine and fenfluramine induce 5-hydroxytryptamine release via a common mechanism blocked by fluoxetine and cocaine. Eur J Pharmacol 215:153-160.

Callaway CW, Kuczenski R, Segal DS (1989) Reserpine enhances amphetamine stereotypics without increasing amphetamine-induced changes in striatal dialysate dopamine. Brain Res 505:83-90.

Church WH, Justice JB Jr (1987) Rapid sampling and determination of extracellular dopamine. Anal Chem 59:712-716.

Cole SO (1978) Brain mechanisms of amphetamine-induced anorexia, locomotion, and stereotypy: a review. Neurosci Biobehav Rev 2:89100.

Creese I, Iversen SD (1974) The role of forebrain dopamine systems in amphetamine-induced stereotypy in the adult rat following neonatal treatment with 6-hydroxydopamine. Psychopharmacology 39: 345-357.

Ferris RM, Tang LM (1979) Comparison of the effects of the isomers of amphetamine, methylphenidate and desoxipradrol on the uptake of $\mathrm{L}-\left[{ }^{3} \mathrm{H}\right]$ norepinephrine and $\left[{ }^{3} \mathrm{H}\right]$ dopamine by synaptic vesicles from rat wholc brain, striatum and hypothalamus. J Pharmacol Exp Ther 210:422-428.

Fischer JF, Cho AK (1979) Chemical release of dopamine from striatal homogenates: evidence for an exchange diffusion model. J Pharmacol Exp Ther 192:642-653.

Florin SM, Kuczenski R, Segal DS (1992) Amphetamine-induced changes in behavior and caudate extracellular acetylcholine. Brain Res 581:53-58.

Florin SM, Kuczenski R, Segal DS (1994) Regional extracellular norepinephrine responses to amphetamine and cocaine and effects of clonidine pretreatment. Brain Res 654:53-62.

Globus MY-T, Busto R, Dietrich WD, Martinez E, Valdés I, Ginsberg MD (1989) Direct evidence for acute and massive norepinephrine release in the hippocampus during transient ischemia. J Cereb Blood Flow Metab 9:892-896.

Green AL, El Hait AS (1980) A new approach to the assessment of the potency of reversible monoamine oxidase inhibitors in vivo, and its application to $(+)$-amphetamine, $p$-methoxyamphetamine and harmaline. Biochem Pharmacol 29:2781-2789.

Heikkila RE, Orlansky H, Mytilineou C, Cohen G (1975) Amphetamine: evaluation of $\mathrm{D}$ - and $\mathrm{L}$-isomers as releasing agents and uptake inhibitors for ${ }^{3} \mathrm{H}$-dopamine and ${ }^{3} \mathrm{H}$-norepinephrine in slices of rat neostriatum and cerebral cortex. J Pharmacol Exp Ther 194:47-56.

Johnson RG, Carty SE, Hayflick S, Scarpa A (1982) Mechanism of accumulation of tyramine, metaraminol, and isoproterenol in isolated chromaffin granules. Biochem Pharmacol 31:815-823.

Kalén P, Kokaia M, Lindvall O, Björklund A (1988) Basic characteristics of noradrenaline release in the hippocampus of intact and 6-hydroxydopaminc-lcsioned rats as studicd by in vivo microdialysis. Brain Res 474:374-379. 
Kalén P, Strecker RE, Rosengren E, Björklund A (1989) Regulation of striatal serotonin release by the lateral habenula-dorsal raphe pathway in the rat as demonstrated by in vivo microdialysis: role of excitatory amino acids and GABA. Brain Res 492:187-202.

Kalisker A, Waymire JC, Rutledge (1975) Effects of 6-hydroxydopamine and reserpine on amphetamine-induced release of norepinephrine in rat cerebral cortex. J Pharmacol Exp Ther 193:64-72.

Kelly PH (1977) Drug-induced motor behavior. In: Handbook of psychopharmacology (Iversen LL, Snyder SH, eds), pp 295-311. New York: Raven.

Kishi T, Inoue T, Suzuki S, Yasuda T, Oikawa T, Niwaguchi T (1983) Analysis of impurities in methamphetamine. Eisei Kagaku 29:400 406.

Knepper SM, Grunewald GL, Rutledge CO (1988) Inhibition of norepinephrine transport into synaptic vesicles by amphetamine analogs. J Pharmacol Exp Ther 247:487-494.

Krueger BK (1990) Kinetics and block of dopamine uptake in synaptosomes from rat caudate nucleus. J Neurochem 55:260-267.

Kuczenski R (1983) Biochemical actions of amphetamine and other stimulants. In: Stimulants: neurochemical, behavioral, and clinical perspectives (Creese I, ed), pp 31-61. New York: Raven.

Kuczenski R, Segal DS (1989) Concomitant characterization of behavioral and striatal neurotransmitter response to amphetamine using in vivo microdialysis. J Neurosci 9:2051-2065.

Kuczenski R, Segal DS (1992a) Regional norepinephrine response to amphetamine using dialysis: comparison to caudate dopamine. Synapse 11:164-169.

Kuczenski R, Segal DS (1992b) Differential effects of amphetamine and dopamine uptake blockers (cocaine, nomifensine) on caudate and accumbens dialysate dopamine and 3-methoxytyramine. J Pharmacol Exp Ther 262:1085-1094.

Kuczenski R, Segal DS (1994) Neurochemistry of amphetamine. In: Amphetamine and its analogues: psychopharmacology, toxicology and abuse (Cho AK, Segal DS, eds), pp 81-113. San Diego: Academic.

Kuczenski R, Segal DS, Manley LD (1990) Apomorphine does not alter amphetamine-induced dopamine release measured in striatal dialysates. J Neurochem 54:1492-1499.

Kuczenski R, Segal DS, Aizenstein ML (1991) Amphetamine, fencamfamine, and cocaine: relationships between locomotor and stereotypy response profiles and caudate and accumbens dopamine dynamics. J Neurosci 11:2703-2712.

Miller HH, Shore PA, Clarke DE (1980) In vivo monoamine oxidase inhibition by D-amphetamine. Biochem Pharmacol 29:1347-1354.

Pehek EA, Schechter MD, Yamamoto BK (1990) Effects of cathinone and amphetamine on the neurochemistry of dopamine in vivo. Neuropharmacology 29:1171-1176.

Pei Q, Zetterström T, Fillenz M (1989) Measurement of extracellular 5-HT and 5-HIAA in hippocampus of freely moving rats using microdialysis: long-term applications. Neurochem Int 15:503-509.

Philippu A, Beyer J (1973) Dopamine and noradrenaline transport in subcellular vesicles of the striatum. Naunyn Schmiedebergs Arch Pharmacol 278:387-402.

Phillips JH (1982) Dynamic aspects of chromaffin granule structure. Neuroscience 7:1595-1609.

Raiteri M, Bertollini A, Angelini F, Levi G (1975) d-Amphetamine as a releaser or reuptake inhibitor of biogenic amines in synaptosomes. Eur J Pharmacol 34:189-195.

Rudnick G, Wall SC (1992) p-Chloroamphetamine induces serotonin release through serotonin transporters. Biochemistry 31:6710-6718.

Rutledge CO (1978) Effect of metabolic inhibitors and ouabain on amphetamine- and potassium-induced release of biogenic amines from isolated brain tissue. Biochem Pharmacol 27:511-516.

Sabol KE, Richards JB, Seiden LS (1992) Fluoxetine attenuates the DL-fenfluramine-induced increase in extracellular serotonin as measured by in vivo dialysis. Brain Res 585:421-424.

Schumann HJ, Philippu A (1962) Release of catecholamines from isolated medullary granules by sympathetic amines. Nature 193:890891.

Segal DS, Kuczenski R (1987) Individual differences in responsiveness to single and repeated amphetamine administration: behavioral characteristics and neurochemical corrclates. J Pharmacol Exp Ther 242: 917-926.

Segal DS, Kuczenski R (1992) In vivo microdialysis reveals a diminished amphetamine-induced dopamine response corresponding to behavioral sensitization produced by repeated amphetamine pretreatment. Brain Res 571:330-337.

Segal DS, Kuczenski R (1994) Behavioral pharmacology of amphetamine. In: Amphetamine and its analogues: psychopharmacology, toxicology and abuse (Cho AK. Segal DS, eds), pp 115-150. San Diego: Academic.

Sessions G, Meyerhoff J, Kant GJ, Koob GF (1980) Effects of lesions of the ventral medial tegmentum on locomotor activity, biogenic amines and response to amphetamine in rats. Pharmacol Biochem Behav 12:603-608.

Stahle L, Segersvärd S, Ungerstedt U (1991) A comparison between three methods for estimation of extracellular concentrations of exogenous and endogenous compounds by microdialysis. J Pharmacol Methods 25:41-52.

Sulzer D, Rayport S (1990) Amphetamine and other psychostimulants reduce $\mathrm{pH}$ gradients in midbrain dopaminergic neurons and chromaffin granules: a mechanism of action. Neuron 5:797-808.

Trendelenburg U (1991) Functional aspects of the neuronal uptake of noradrenaline. Trends Pharmacol Sci 12:334-337.

Van Veldhuizen MJA, Feenstra MGP, Boer GJ, Westerink BHC (1990) Microdialysis studies on cortical noradrenaline release: basic characteristics, significance of extracellular calcium and massive postmortem increase. Neurosci Lett 119:233-236.

Wages SA, Church WH, Justice JB Jr (1986) Sampling considerations for on-line microbore liquid chromatography of brain dialysis. Anal Biochem 58:1649-1656.

Zaczek R, Culp S, De Souza EB (1991) Interactions of [ $\left.{ }^{3} \mathrm{H}\right]$ amphetamine with rat brain synaptosomes. II. Active transport. J Pharmacol Exp Ther 257:830-835.

Zetterstrom T, Sharp T, Marsden CA, Ungerstedt U (1983) In vivo measurement of dopamine and its metabolites by intracerebral dialysis: changes after d-amphetamine. J Neurochem 41:1769-1773.

Zetterstrom T, Sharp T, Ungerstedt U (1986) Further evaluation of the mechanism by which amphetamine reduces striatal dopamine metabolism: a brain dialysis study. Eur J Pharmacol 132:1-9. 